\title{
Demystifying the Biochemistry: Theoretical Concepts and Practical Activities for High School
}

Bard, C.S. ${ }^{1}$; Souza-Galossi, F. ; Deus-de-Oliveira, N. ${ }^{1,2}$, Machado, O.L.T. ${ }^{1}$

${ }^{1}$ LQFPP/CBB/UENF, RJ, Brazil; ${ }^{2}$ IFF - campus Campos-Centro, RJ, Brazil

INTRODUCTION: The education goes through a crisis in their teaching-learning process, due to the fact that their contents are developed out of context, merely theoretical activities. Several scholars warn about the importance of working with experiential activities to enhance and stimulate student learning, seeking a more meaningful than we have seen in recent times. The objectives of this work are installation of a laboratory for teaching science in public school, ISEPAM, at North of Rio de Janeiro, formation of multipliers agents and promoting a Scientific Week/Exhibition involving all school community. MATERIALS AND METHODS: First, we perform the spatial organization of the laboratory, including purchase of materials/equipment. In a second step, experimental activities involving identification of Macromolecules in foods were prepared and tested. From this, we promote short courses in biochemistry for teachers to forming multiplier agents. As a conclusion of the activities of this project a Scientific Week/Exhibition was promoted in school. RESULTS AND DISCUSSION: Practical classes on fermentation, identification of lipids, proteins and carbohydrates were performed by teachers and students from ISEPAM. We observed in the biochemistry course which the participants have established relationships between theory and practice and also they showed interest in the insertion of experiments in their work routine.. Regarding the Scientific Week/Exhibition, students of elementary and high school participated. They were encouraged and integrated with experiment activities and thereby new talents for scientific and technological interest were identified. CONCLUSION: It was observed that the experimental activities become more attractive and challenging the search for knowledge.

Key-words: Experimental activities, Biological Macromolecules, Multiplier Agents. Supported by: FAPERJ and UENF 